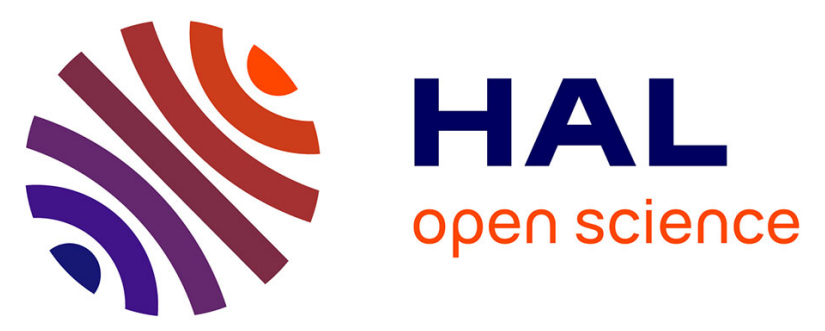

\title{
Chest tcpO2 changes during constant-load treadmill walking tests in patients with claudication
}

N Ouedraogo, Mathieu Feuilloy, Guillaume Mahe, Georges Leftheriotis, Jean-Louis Saumet, Pierre Abraham

\section{- To cite this version:}

N Ouedraogo, Mathieu Feuilloy, Guillaume Mahe, Georges Leftheriotis, Jean-Louis Saumet, et al.. Chest tcpO2 changes during constant-load treadmill walking tests in patients with claudication. Physiological Measurement, 2011, 32 (2), pp.181-194. 10.1088/0967-3334/32/2/003 . hal-01164597

\section{HAL Id: hal-01164597 \\ https://hal.science/hal-01164597}

Submitted on 27 Jan 2018

HAL is a multi-disciplinary open access archive for the deposit and dissemination of scientific research documents, whether they are published or not. The documents may come from teaching and research institutions in France or abroad, or from public or private research centers.
L'archive ouverte pluridisciplinaire $\mathbf{H A L}$, est destinée au dépôt et à la diffusion de documents scientifiques de niveau recherche, publiés ou non, émanant des établissements d'enseignement et de recherche français ou étrangers, des laboratoires publics ou privés. 


\title{
Chest tcpO $\mathrm{O}_{2}$ changes during constant-load treadmill walking tests in patients with claudication
}

\author{
N Ouedraogo ${ }^{1,2}$, M Feuilloy ${ }^{3}$, G Mahe $^{2}$, G Leftheriotis ${ }^{1,2}$, \\ J-L Saumet ${ }^{4}$ and P Abraham ${ }^{1,2,5}$ \\ ${ }^{1}$ Laboratory of Physiology, CNRS, UMR6214, Angers, F-49045 France, Inserm, U771, Angers, \\ F-49045 France, Medical School, University of Angers, Angers, F-49045, France \\ ${ }^{2}$ Laboratory for Vascular Investigations, University Hospital, Angers Cedex 01, F-49033, France \\ ${ }^{3}$ Superior School for Electronics, ESEO, Angers, France \\ ${ }^{4}$ FRE CNRS 3075, Lyon 1, France
}

\begin{abstract}
Changes in chest transcutaneous- $\mathrm{pO}_{2}$ at rest $\left(\Delta \mathrm{tcpO} \mathrm{O}_{2}\right)$ mimic absolute changes in arterial- $\mathrm{pO}_{2}$ during moderate exercise, although the absolute starting values may dramatically differ. We retrospectively studied 485 patients (group 1), prospectively studied 292 new patients (group 2) and estimated the intra-test and the test-retest reproducibility of $\Delta \mathrm{tcpO}_{2}$ during constant-load treadmill tests: $3.2 \mathrm{~km} \mathrm{~h}^{-1}, 10 \%$ grade, using the cross correlation technique. Patients were classified into groups according to their best fit to nine pre-defined mathematic models. Respectively, $71 \%$ and $76 \%$ of patients of groups 1 and 2 fitted with a model showing a $\Delta \mathrm{tcpO}_{2}$ increase during and a decrease following exercise. Another $18 \%$ and $12 \%$ of the patients of groups 1 and 2 respectively fitted with a model that showed an abrupt decrease at exercise onset, a slow increase during walking and an overshoot in the recovery period, referred here as a walking-induced transcutaneous hack (WITH) profile. The mean $r_{\max }$ value for the cross-correlation analysis was $0.919 \pm 0.091$ and $0.800 \pm 0.129$ for intra-test and test-retest reproducibility. Most profiles show the expected $\Delta \mathrm{tcpO}_{2}$ exercise-induced increase. Future studies are needed to confirm and explain the WITH profiles that we found, and screen for potential-associated diseases.
\end{abstract}

Keywords exercise testing, physiopathology, methods, exercise intolerance, classification

5 Author to whom any correspondence should be addressed. 


\section{Introduction}

Lower limb claudication can result from various diseases such as peripheral artery disease, exercise-induced hypoxemia or lumbar spine stenosis. Hypoxemia can result in limb pain while walking sometimes without associated dyspnoea (Killian et al 1992). When occurring as a result of systemic exercise-related hypoxemia, limb pain is likely to fulfil vascular-type characteristics. Pulmonary disease and vascular disease share a number of common risk factors (age, overweight, tobacco). All patients with pulmonary disease do not have hypoxemia but $15 \%$ of patients with peripheral artery disease (PAD) (von Kemp et al 1997, Heidrich 2004) or undergoing cardiac surgery (Clough et al 2002) have pulmonary disease. Thus detecting abnormal arterial $\mathrm{pO}_{2}$ response to exercise might be of interest in patients with claudication as a potential patho-physiological mechanism mimicking or aggravating claudication of arterial origin.

The $t c \mathrm{PO}_{2}$ technique, although not a primary care technique, is used in patients with claudication to argue for a vascular origin of pain, detect buttock ischemia or estimate the effect of rehabilitation programmes (Caillard et al 1990, Abraham et al 2003, 2005). The transcutaneous oxygen pressure $\left(\mathrm{tcpO}_{2}\right)$ technique is an old technique initially proposed in neonates to non-invasively estimate arterial $\mathrm{pO}_{2}$. Although a complex and time-consuming technique as compared to pulse oxymetry (saturometry), it is expected of advantage as compared to saturometry to detect abnormal arterial oxygen changes at exercise. Indeed, keeping in mind the sigmoid relationship between oxygen pressure and oxygen saturation in human blood, arterial saturation may remain in normal limit despite a significant decrease in arterial $\mathrm{pO}_{2}$, specifically in patients with normal arterial $\mathrm{pO}_{2}$ at rest. Further intra-arterial blood sampling cannot be proposed as a screening technique of eventual abnormal $\mathrm{pO}_{2}$ changes in all patients suffering exercise intolerance.

There is multiple evidence that chest tcpO $\mathrm{O}_{2}$ changes at rest $\left.(\Delta \mathrm{tcpO})_{2}\right)$ mimic the changes in arterial $\mathrm{pO}_{2}$ at rest during mild or moderate exercise (McDowell and Thiede 1980, Hughes et al 1984, Hutchison et al 1987, Sridhar et al 1993, Brudin et al 1994, Carter and Banham 2000, Planes et al 2001) despite the presence of an unpredictable transcutaneous gradient and provided that the changes are relatively slow ( $90 \%$ time response of $\mathrm{tcpO}_{2}$ being $\sim 20 \mathrm{~s}$ ). During constant-load exercise, if one aims at estimating only the absolute changes in arterial $\mathrm{pO}_{2}$ at rest overtime regardless of the initial starting absolute value, then the transcutaneous technique is accurate. When used during exercise in patients with claudication, limb tcpO changes are usually analysed in comparison to tcpO $\mathrm{O}_{2}$ changes observed with a reference probe on the chest, either by dividing the limb tcpO $\mathrm{O}_{2}$ value by the chest $\mathrm{tcpO}_{2}$ value (Osmundson et al 1988, Arnold et al 1993) or subtracting chest changes from limb changes (Abraham et al 2003, 2005, Gelis et al 2009). In both cases, the potential information available in the chest signal itself is lost. To the best of our knowledge, specific analysis of chest $\Delta \mathrm{tcpO}_{2}$ profiles in patients undergoing treadmill walking tests has never been reported. We hypothesized that analysing $\Delta \mathrm{tcpO}_{2}$ changes could provide new insights into the mechanisms of exercise intolerance in patients reporting claudication provided that an easy and observer-independent classification of $\Delta \mathrm{tcpO}_{2}$ changes can be performed, that the classification is reliable and that $\Delta \mathrm{tcpO} \mathrm{O}_{2}$ changes are specific of each patient's response to exercise.

We performed a series of experiments to: (1) propose a classification of $\Delta \mathrm{tcpO}_{2}$ profiles based on a cross-correlation observer-independent approach, using an excel spreadsheet, (2) test the reliability of the distribution of $\Delta \mathrm{tcpO}_{2}$ profiles types with this technique in a population different from the initially studied group, (3) evaluate the intra-test reproducibility of $\Delta t c p \mathrm{O}_{2}$ changes using two probes to ascertain that changes observed are independent of the probe position on the chest, and (4) analyse the reproducibility of $\Delta \mathrm{tcpO}_{2}$ profiles in test-retest 
experiments to check whether or not each profile is a reproducible characteristic of each patient's response to the walking test.

\section{Methods}

\subsection{Experiment 1}

2.1.1. Population. We retrospectively analysed all consecutive 485 different patients referred for exercise-induced vascular-type claudication and those who had undergone a standard treadmill walking test with tcpO $\mathrm{O}_{2}$ recording including a chest probe over a 3 years period, starting April 2006. Vascular-type claudication is defined as a pain in the lower limb that is absent at rest, is induced by exercise and disappears within 10 min when exercise is stopped. Results from non-invasive vascular investigations (ankle to brachial systolic blood pressure index: $\mathrm{ABI}$ ), medical history, treatments were retrieved from patient's files, but were not made known at the time of exercise test analyses.

2.1.2. Exercise test. The treadmill tests started with a $120 \mathrm{~s}$ resting period in the standing position. Then, tests were performed using a $10 \%$ slope and a constant $3.2 \mathrm{~km} \mathrm{~h}^{-1}$ speed (reached within $1 \mathrm{~min}$ to facilitate the patient's adaptation). Patients were encouraged to perform the test for the longest time possible. Exercise was discontinued at the patient's request (limiting symptoms), or in the absence of limiting symptoms, after a total walking duration of $20 \mathrm{~min}$. A 10 min recovery period was observed in the standing position after the end of the exercise test.

2.1.3. Transcutaneous recording. After a 20 min resting period, patients were installed in a room with a temperature of $21 \pm 2{ }^{\circ} \mathrm{C}$. Measurements were performed using the TINA TCM400 tcpO ${ }_{2}$ devices (Radiometer, DK). A one-point calibration to air was performed three times before each experiment. The temperature of the probe was set to $44.5^{\circ} \mathrm{C}$ to allow maximal local vasodilatation, thereby decreasing the arterial to skin surface oxygen pressure gradient. Afterwards, the $\mathrm{tcpO}_{2}$ measurements were automatically temperature-corrected to $37^{\circ} \mathrm{C}$ by the TINA device. The electrode was placed over the right scapula on the back, except in patients that have had a right thoracotomy. In this case, the probe was placed on the left side.

A pre-test heating period of 15 to 20 min with the patient standing on the treadmill was required to allow stable tcpO $\mathrm{O}_{2}$ resting values to be reached and local heating of the skin. The data were recorded every $2 \mathrm{~s}$ throughout the test and transferred to a spreadsheet on personal computers for analysis. From the spreadsheet of each patient, we noted the exact duration of exercise as well as the average absolute tcpO $\mathrm{O}_{2}$ value over the resting period (REST). Then the REST value was subtracted from all data points and results expressed as the difference from baseline $\left(\Delta \mathrm{tcpO}_{2}: \mathrm{mmHg}\right)$.

2.1.4. Construction of the models. From previous experiments, we noted that most changes in $\mathrm{tcpO}_{2}$ lied within -10 and $+15 \mathrm{mmHg}$ from the REST value and that end-recording values were on the average $10 \mathrm{mmHg}$ higher than the REST values. Then, for each patient, nine different models were automatically generated using a home-made program that constructed models according to the presence or absence and to different positions of the maximal $(+15)$ and minimal $(-10)$ values in the model. The models all started with a 2 min zero value from the point $\mathrm{X}$ and ended at $Z=+10$; see figure 1 . The first point of interest $\mathrm{Pa}$ was fixed at 


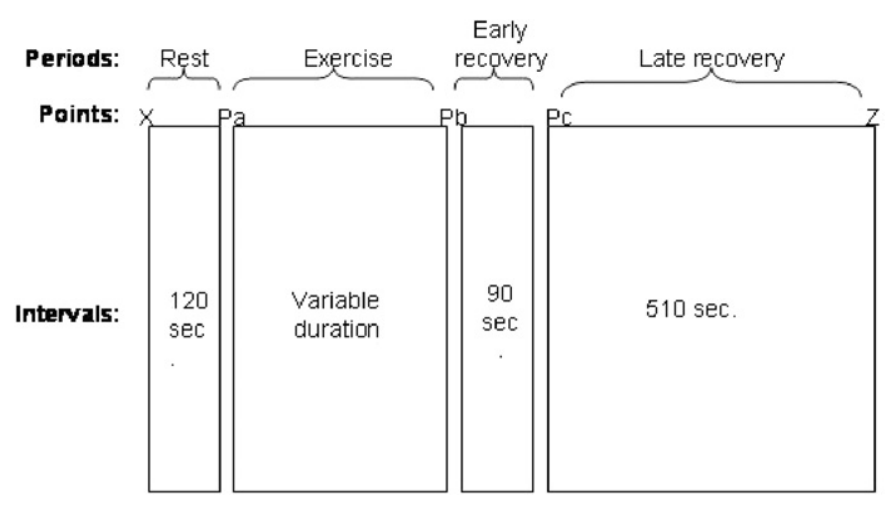

Figure 1. Diagram of the different intervals defined for the models to mimic the periods of treadmill tests. See the text for further details.

2 min and $\mathrm{Pb}$ at 10 min before $\mathrm{Z}$. The $\mathrm{Pa}-\mathrm{Pb}$ interval adapted to the exercise duration of each patient. The $\mathrm{Pb}$-to- $\mathrm{Z}$ interval was arbitrarily divided into a first $90 \mathrm{~s} \mathrm{~Pb}-\mathrm{Pc}$ interval followed by a $510 \mathrm{~s} \mathrm{Pc-Z}$ interval since we previously noted that when $\mathrm{tcpO}_{2}$ increased during exercise, the highest test value was generally observed approximately one and a half minute after the end of exercise.

The program automatically generated models according to various positions of the maximal and minimal values at $\mathrm{Pa}, \mathrm{Pb}$ or $\mathrm{Pc}$. An example of the nine models generated for exercise durations of $6.33 \mathrm{~min}$ is presented in figure 2. For each patient, the program produced a nine-column spreadsheet, one for each model, with one point every $2 \mathrm{~min}$ to fit with the recording sample rate for tcpO $\mathrm{C}_{2}$. A special function was included in the program to smooth the generated curves with a log function to account for the half-time response of the tcpO $\mathrm{O}_{2}$ probes to abrupt changes in $\mathrm{PO}_{2}$ (Grouiller et al 2006).

2.1.5. Analysis of the data. For each patient, a comparison of each subject's $\Delta \operatorname{tcpO}_{2}$ changes to each of the different models was performed with the cross correlation technique using an Excel sheet with cross correlation over \pm 15 data points. In the cross correlation analysis, the highest ' $r$ ' correlation coefficient $\left(r_{\max }\right)$ is equal to Pearson's coefficient. All patient curves were compared to models 1 and 2 but a minimal decrease at rest of $2 \mathrm{mmHg}$ was required to compare the patient profile to models 3 to 9 . This was performed to account for eventual small short-lived physiological or technical changes in recorded transcutaneous values or for a progressive downward drift of $\mathrm{tcpO}_{2}$, in order to avoid misclassification. Thereafter, patients were classified by groups according to the number of the models to which their $\Delta \mathrm{tcpO}_{2}$ profile showed the highest $r_{\max }$ value (best- $r_{\max }$ ). A best- $r_{\max }$ value $>0.650$ was arbitrarily fixed to define a good fitting.

\subsection{Experiment 2}

What we aimed here was to estimate whether the group distribution of the different $\Delta \mathrm{tcpO}_{2}$ profile types observed in experiment 1 was found comparable in another group.

2.2.1. Population. A prospective analysis was carried out on all consecutive different patients referred for exercise-induced vascular-type lower limb pain and those who had undergone a 


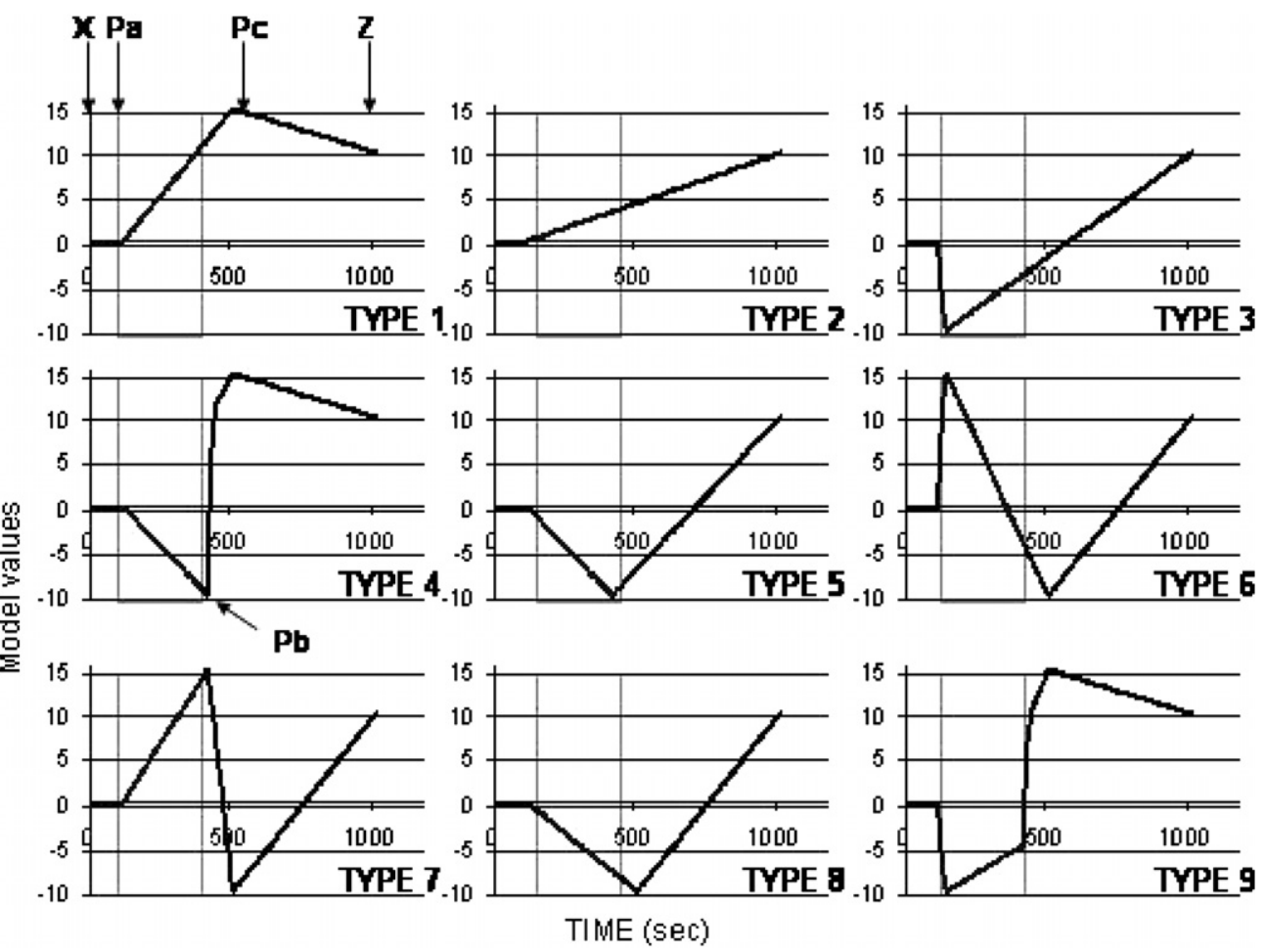

Figure 2. Example of nine automatically generated models with an exercise duration of $304 \mathrm{~s}$. Gray squares are exercise periods. And examples of the points of interests $\mathrm{X}, \mathrm{Z}, \mathrm{Pa}, \mathrm{Pb}$ and $\mathrm{Pc}$.

standard treadmill walking test with $\mathrm{tcpO}_{2}$ recording at the chest level. As in experiment 1 , results from non-invasive vascular investigations (ankle to brachial systolic blood pressure index: $\mathrm{ABI}$ ), medical history, treatments were retrieved from the patient's files, but were not made known at the time of exercise test analyses.

2.2.2. Exercise test and transcutaneous recording. The treadmill tests and tcpO $\mathrm{O}_{2}$ recordings were performed as in experiment 1 . We prospectively included all new patients referred to the laboratory in the period: April 2009 to February 2010.

2.2.3. Analysis of the data. Fitting of the values was performed by comparing recorded values to the same nine different automatically generated models as in experiment 1 . As in experiment 1 , a best- $r_{\max }>0.650$ was used to define a good fitting and the classification repeated for patients with a best- $r_{\max }>0.650$. Pearson's chi-square test was used to compare the distribution of profiles among the four most-represented groups of the present population with the distribution observed in experiment 1 .

2.2.4. Sample size estimation. We aimed to have at least ten patients in each of the four most represented groups even in patients with best- $r_{\max }>0.650$ to allow for the chi-square comparison with our previous results. According to the profile-type distribution, confidence 
intervals and proportion of patients with prevalence best- $r_{\max }>0.650$ previously observed, the minimal number of subjects to be analysed in experiment 2 was 250 .

\subsection{Experiment 3}

2.3.1. Population. This experiment was carried out with the hypothesis that the absolute starting value might differ from one probe position to another, but that the profiles at the level of the two probes will be comparable. We aimed to confirm that $\Delta \mathrm{tcpO}_{2}$ changes are independent of starting $\mathrm{pO}_{2}$ absolute value and thus of the exact probe position.

2.3.2. Exercise test and transcutaneous recording. Exercise testing and transcutaneous $\mathrm{pO}_{2}$ recording were performed as in experiments 1 and 2 but a second probe was positioned on the chest, at least $5 \mathrm{~cm}$ from the first probe.

2.3.3. Analysis of the data. The cross correlation was performed over \pm 15 data points. In this experiment, values for $r_{\max }>0.8, r_{\max }$ between 0.5 and 0.8 , and $r_{\max } \leqslant 0.5$ were used to define excellent, satisfactory and unsatisfactory profile reproducibility, respectively.

2.3.4. Sample size estimation. We estimated the mean Pearson coefficient of correlation to be 0.85 or more with a type 1 error of $5 \%$ and a power of $90 \%$ (two-sided hypothesis). The minimal number of subjects to be analysed was 10 (Machin et al 1997).

\subsection{Experiment 4}

2.4.1. Population. The reproducibility of the chest $\Delta \mathrm{tcpO}_{2}$ profile during walking was studied through test-retest recordings separated by a minimum of 1 month. In this test-retest prospective study a signed informed consent was obtained from each patient.

2.4.2. Exercise test and transcutaneous recording. Exercise testing and transcutaneous $\mathrm{pO}_{2}$ recording were performed as in the other experiments. It should be noted that the exact position of the probe to be used for the second test was not recorded during the first test.

2.4.3. Analysis of the data. The data analysis and classification of the quality of the results were performed as for experiment 3 (see section 2.3.3).

2.4.4. Sample size estimation. We estimated the mean $r_{\max }$ to be 0.75 or more with a type 1 error of $5 \%$ and a power of $90 \%$ (two-sided hypothesis). The minimal number of subjects to be analysed was 15 (Machin et al 1997).

\subsection{Ethical considerations}

The protocols were approved by the ethic's committee and conform to Helsinki Declaration. As observational studies, no informed consent was required from patients in experiments 1 and 2. The prospective studies presented in experiments 3 and 4 were performed as specific analyses of the 'Evaluation Objective des Ischémies Proximales' (EOIP) study; NIH database: NCT00152737, and a signed informed consent was obtained from each patient. 


\subsection{Statistical analysis}

Data management and cross correlation were performed with an Excel spreadsheet. Statistical analysis for $t$-tests and chi-square tests were carried out with SPSS V15.0. Results are expressed in mean $\pm \mathrm{SD}$. For all statistical tests, a two-tailed probability level of $P<0.05$ was used to indicate statistical significance. Non-significant results are reported N.S.

\section{Results}

\subsection{Experiment 1}

The patients studied were 420 males/ 65 females, aged $61.4 \pm 11.1$ years, height $169 \pm 8 \mathrm{~cm}$, weight $77 \pm 14 \mathrm{~kg}$. The lowest (right or left) measurable ankle to brachial index was $0.80 \pm$ 0.24 . Co-morbid conditions included history of vascular surgery $(n=146)$, diabetes mellitus $(n=80)$, coronary disease or cardiac surgery $(n=85)$, history of minor stroke or carotid surgery $(n=47)$, and chronic pulmonary disease $(n=30)$. Treatments included anti- platelet or anti-coagulant drugs $(n=387)$, cholesterol-lowering agents $(n=266)$, converting enzyme inhibitors or sartans $(n=182)$, beta blockers $(n=88)$, anti-diabetic agents $(n=80)$, antihypertensive drugs $(n=64)$, and broncho-dilators $(n=20)$. On the average, the maximal walking distance on treadmill over the whole group was $364 \pm 326 \mathrm{~m}$. All patients walked at least $1.5 \mathrm{~min}$. On treadmill, 395 patients could not complete the $20 \mathrm{~min}$ of the test and showed exercise limitation. Among the 90 patients who completed the $20 \mathrm{~min}$ of the test, 46 were completely asymptomatic and 44 had non-limiting claudication.

The chest tcpO $\mathrm{O}_{2}$ REST value was $66.8 \pm 12.4 \mathrm{mmHg}$. Figures 3 and 4 show examples of different profiles and of cross-correlation coefficients obtained. Figure 5 shows the distribution of best- $r_{\max }$ values in the population. The median best- $r_{\max }$ among the 485 patients was 0.870 . Most of the low best- $r_{\max }$ values resulted from patients showing almost flat $\Delta \mathrm{tcpO}_{2}$ profiles, some others from patients who showed ample, apparently random, oscillations of $\Delta \mathrm{tcpO} \mathrm{P}_{2}$. As shown in table 1, four models (1, 2, 4 and 9) were observed in $94.8 \%$ of the 485 patients and the models rarely found were often those for which the best- $r_{\max }$ was low. Thereafter, in patients with best- $r_{\max }>0.650$, more than $97 \%$ of the patients were classified into only four groups. Among the four most represented groups, more than half $(60.4 \%)$ of the 419 patients were kept in group 1.

\subsection{Experiment 2}

The studied patients were 238 males $/ 54$ females, aged $63.6 \pm 11.51$ years, height $169 \pm 8 \mathrm{~cm}$, weight $76 \pm 15 \mathrm{~kg}$. The lowest (right or left) measurable ankle to brachial index was 0.77 \pm 0.24 . Co-morbid conditions included history of aortic or lower limb vascular surgery $(n$ $=115)$, diabetes mellitus $(n=67)$, coronary disease or previous cardiac surgery $(n=29)$, history of minor stroke or carotid surgery $(n=11)$, arthritis $(n=15)$, chronic pulmonary disease $(n=12)$, sciatica or lumbar spine syndrome $(n=23)$ or cancer $(n=32)$. Treatments included anti-platelet or anti-coagulant drugs $(n=237)$, cholesterol-lowering agents $(n=$ $192)$, converting enzyme inhibitors or sartans $(n=164)$, beta blockers $(n=83)$, anti-diabetic agents $(n=63)$, anti-hypertensive drugs $(n=29)$, and broncho-dilators $(n=18)$.

On the average, the maximal walking distance on treadmill over the whole group was $280 \pm 284 \mathrm{~m}$. All patients walked at least $1.5 \mathrm{~min}$. On treadmill, 263 of the 292 patients could not complete the $20 \mathrm{~min}$ of the test and showed exercise limitation. Of these, although all patients were referred for claudication, 236 reported lower limb pain with $(n=35)$ or without $(n=201)$ non-vascular symptoms such as fatigue dyspnoea or dizziness; the other 27 


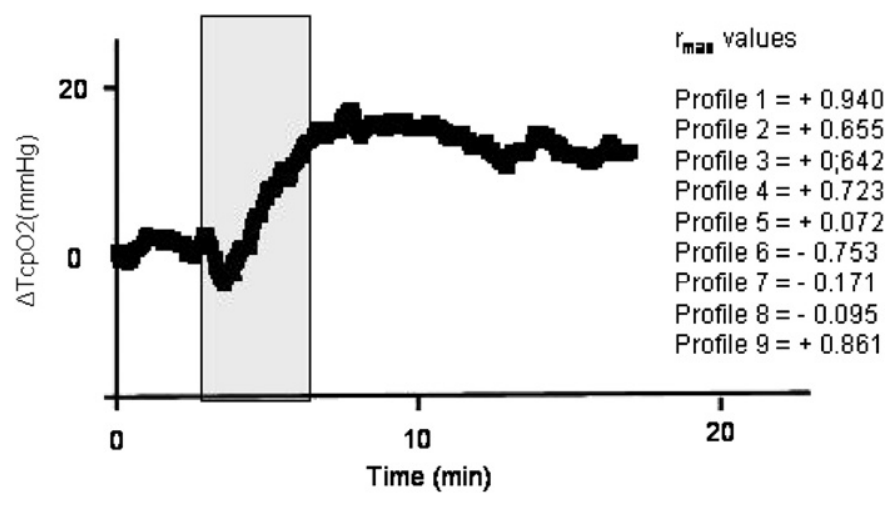

Figure 3. Example of $\mathrm{tcpO}_{2}$ changes from rest $(\Delta \mathrm{tcpO})$ in a patient performing a $5 \mathrm{~min}$ and $4 \mathrm{~s}$ $(304 \mathrm{~s})$ test. The minimal $\Delta \mathrm{tcpO}_{2}$ for this patient was minus $3 \mathrm{mmHg}$. The figure shows the different $r_{\max }$ values obtained for this patient for each of the nine models shown in figure 2 . The best- $r_{\max }$ for this patient was observed with profile type 1 . Grey squares is the exercise period.

Table 1. Number of patients from experiment 1, classified in each of the nine model types with the mean \pm SD of best- $r_{\max }$ found in the patients within each type before and after exclusion of the 66 patients for which the best- $r_{\max }$ was lower than 0.650 .

\begin{tabular}{|c|c|c|c|c|c|c|}
\hline \multirow[b]{2}{*}{ Model type } & \multicolumn{3}{|c|}{ All patients $(n=485)$} & \multicolumn{3}{|c|}{$\begin{array}{l}\text { Patients with best }-r_{\max }>0.650 \\
\qquad(n=419)\end{array}$} \\
\hline & $n$ & $\%$ & Mean \pm SD & $n$ & $\%$ & Mean \pm SD \\
\hline 1 & 298 & $61.4(57.0-65.8)$ & $799 \pm 185$ & 253 & $60.4(55.5-65.1)$ & $864 \pm 80$ \\
\hline 2 & 51 & $10.5(7.3-13.6)$ & $795 \pm 146$ & 45 & $10.7(7.9-14.1)$ & $836 \pm 75$ \\
\hline 3 & 7 & $1.4(0.6-3.0)$ & $865 \pm 80$ & 7 & $1.7(0.7-3.4)$ & $865 \pm 80$ \\
\hline 4 & 33 & $6.8(4.7-9.4)$ & $877 \pm 125$ & 32 & $7.6(5.3-10.6)$ & $897 \pm 52$ \\
\hline 5 & 4 & $0.8(0.2-2.1)$ & $777 \pm 110$ & 3 & $0.7(0.2-2.1)$ & $824 \pm 68$ \\
\hline 6 & 4 & $0.8(0.2-2.1)$ & $472 \pm 195$ & 0 & $0.0(0.0-0.0)$ & - \\
\hline 7 & 8 & $1.6(0.7-3.2)$ & $445 \pm 199$ & 1 & $0.2(0.0-1.3)$ & 750 \\
\hline 8 & 2 & $0.4(0.1-1.5)$ & $734 \pm 292$ & 1 & $0.2(0.0-1.3)$ & 940 \\
\hline 9 & 78 & $16.1(12.9-19.7)$ & $897 \pm 68$ & 77 & $18.4(14.8-22.4)$ & $901 \pm 60$ \\
\hline
\end{tabular}

reported no lower limb limiting symptoms among which 13 reported dyspnoea. Among the 29 patients who could complete the $20 \mathrm{~min}$ of the test, 16 were completely asymptomatic and $13 \mathrm{had}$ non-limiting claudication. The chest $\mathrm{tcpO}_{2}$ value at rest was $68.3 \pm 12.0 \mathrm{mmHg}$.

As shown in table 2, four models (types 1, 2, 4 and 9) were observed in $91.8 \%$ of the 292 patients. As in the first population studied, the models rarely found (3, 5, 6, 7 and 8) were mainly those for which the best- $r_{\max }$ was low, specifically for type 6 and 7 models. Thereafter, after exclusion of the 46 patients with low best- $r_{\max }, 94 \%$ of the patients were classified in one of the four groups corresponding to models types 1,2, 4 and 9. Among these four most represented groups, $65.4 \%$ of the 231 patients were kept in group 1 (best correlation with type 1 profiles). Only $6 \%$ of the patients were classified into groups 3, 5, 7 or 8 and no patient was kept in group 6.

No difference was found in the distribution of the patients within the four most frequent groups (1, 2, 4 and 9) as compared to the distribution observed in experiment 1, either before 

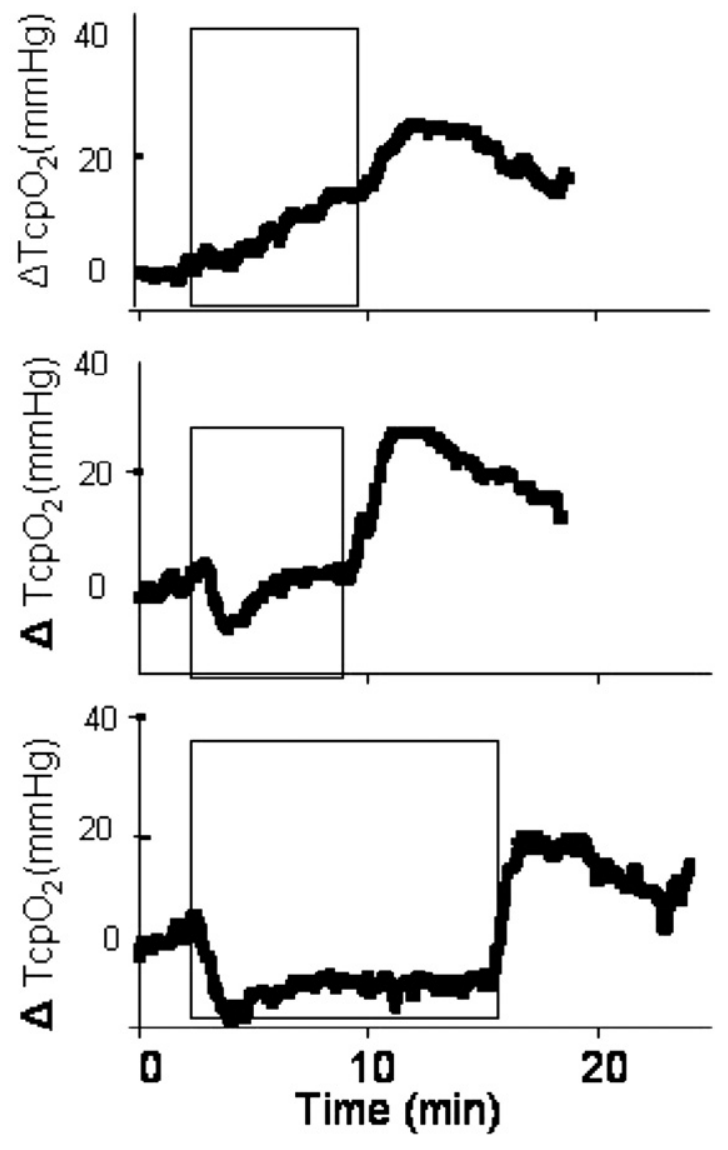

Figure 4. Typical examples of type 1 (upper graph) and type 9 (middle and lower graphs) $\mathrm{tcpO}_{2}$ changes from rest $\left(\Delta \mathrm{tcpO}_{2}\right)$. Grey squares are exercise periods.

$\left(\chi^{2}=7.1, p=0.07\right)$ and after $\left(\chi^{2}=7.3 ; p=0.06\right)$ exclusion of profiles with a best $r_{\max } \leqslant$ 0.650 .

\subsection{Experiment 3}

We tested 15 patients: 14 males and 1 female, aged $63 \pm 11$ years, height $167 \pm 8 \mathrm{~cm}$, weight $73 \pm 12 \mathrm{~kg}$. The tcpO $\mathrm{P}_{2}$ value at rest was $63.9 \pm 7.1 \mathrm{mmHg}$ on probe 1 and $63.2 \pm$ 10.7 on probe 2 (N.S). Although mean values were not different, on the average the absolute differences in $\mathrm{tcpO}_{2}$ between the two probes were $4.4 \pm 6.8 \mathrm{mmHg}$. The mean $r_{\max }$ value for the cross correlation analysis for the 15 analysed pairs of profiles was $0.919 \pm 0.091$. Then, a very high correlation exists between the profiles obtained from two different probes in the same patient, despite eventual differences in absolute starting values.

\subsection{Experiment 4}

We studied 31 patients (28 males and 3 females), aged $63 \pm 11$ years, height $168 \pm 6 \mathrm{~cm}$, weight $73 \pm 13 \mathrm{~kg}$. All these patients had stable claudication and had no surgery or change 


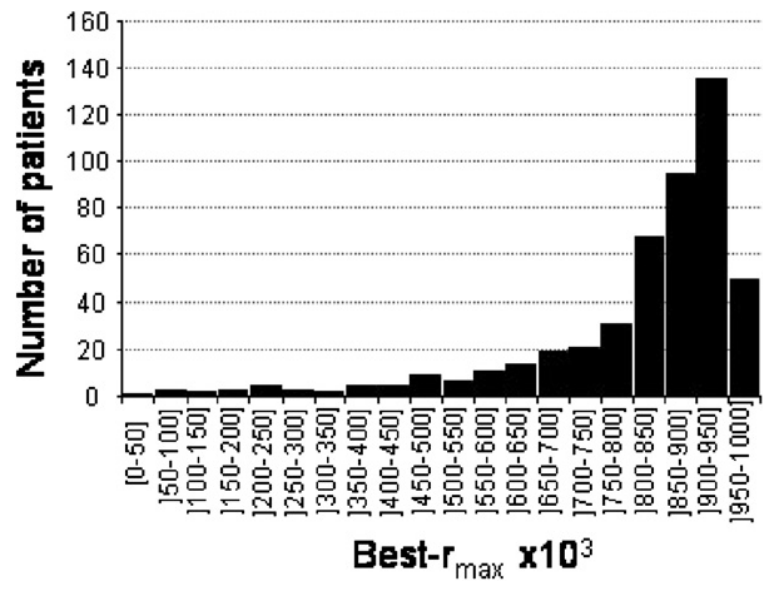

Figure 5. The distribution of best- $r_{\max }$ values obtained for the 485 patients.

Table 2. Number of patients from experiment 2, classified in each of the nine model types with the mean \pm SD of best- $r_{\max }$ found in the patients within each type before and after exclusion of the 46 patients for which the best- $r_{\max }$ was lower than 0.650 .

\begin{tabular}{lrlllll}
\hline & \multicolumn{4}{c}{ All patients $(n=292)$} & \multicolumn{3}{c}{$\begin{array}{c}\text { Patients with best- } r_{\max }>0.650 \\
(n=246)\end{array}$} \\
Model type & \multicolumn{1}{c}{$n$} & $\%$ & Mean \pm SD & \multicolumn{1}{c}{$\%$} & $\%$ & Mean \pm SD \\
\hline 1 & 180 & $61.6(56.0-67.0)$ & $794 \pm 181$ & 151 & $61.4(55.2-67.3)$ & $859 \pm 80$ \\
2 & 42 & $14.4(10.8-18.9)$ & $797 \pm 145$ & 37 & $15.0(11.1-20.1)$ & $835 \pm 76$ \\
3 & 5 & $1.7(0.6-4.1)$ & $767 \pm 202$ & 4 & $1.6(0.5-4.3)$ & $854 \pm 64$ \\
4 & 16 & $5.5(3.3-8.8)$ & $828 \pm 117$ & 14 & $5.7(3.3-9.4)$ & $862 \pm 78$ \\
5 & 4 & $1.4(0.4-3.6)$ & $818 \pm 65$ & 4 & $1.6(0.5-4.3)$ & $818 \pm 65$ \\
6 & 1 & $0.3(0.0-2.1)$ & 466 & 0 & $0.0(0.0-0.0)$ & - \\
7 & 8 & $2.7(1.3-5.4)$ & $472 \pm 185$ & 1 & $0.4(0.0-2.5)$ & 710 \\
8 & 6 & $2.1(0.8-4.5)$ & $843 \pm 44$ & 6 & $2.4(1.0-5.3)$ & $843 \pm 44$ \\
9 & 30 & $10.3(7.3-14.3)$ & $883 \pm 91$ & 29 & $11.8(8.3-16.5)$ & $892 \pm 78$ \\
\hline
\end{tabular}

in their treatment between the two tests. The lowest ABI in this group was $0.72 \pm 0.22$. The median delay between the two tests was 5 months (1-9 months). The duration of the walking period was $6.2 \pm 4.9 \mathrm{~min}$ for test 1 and $6.1 \pm 4.4$ for test $2(\sim 320 \mathrm{~m})$. The $\mathrm{tcpO}_{2}$ value at rest was $67.4 \pm 10.7 \mathrm{mmHg}$ on test 1 and $69.3 \pm 11.8$ on test 2 (N.S). Although mean values were not different, on the average the absolute differences in $\mathrm{tcpO}_{2}$ between the two tests were $9.5 \pm 7.1 \mathrm{mmHg}$. The $r_{\max }$ value for the cross correlation analysis for the 31 analysed pairs of profiles was $0.800 \pm 0.129$. Twenty patients showed an excellent reproducibility $\left(r_{\max }>0.8\right)$, nine patients had a satisfactory reproducibility and two patients an unsatisfactory reproducibility. The low $r_{\max }$ coefficient for these latter two patients was related to the fact that $\Delta \mathrm{tcpO}_{2}$ showed very little change during exercise except apparently random oscillations around baseline values. The examples of test-retest recordings are presented in figure 6 . 


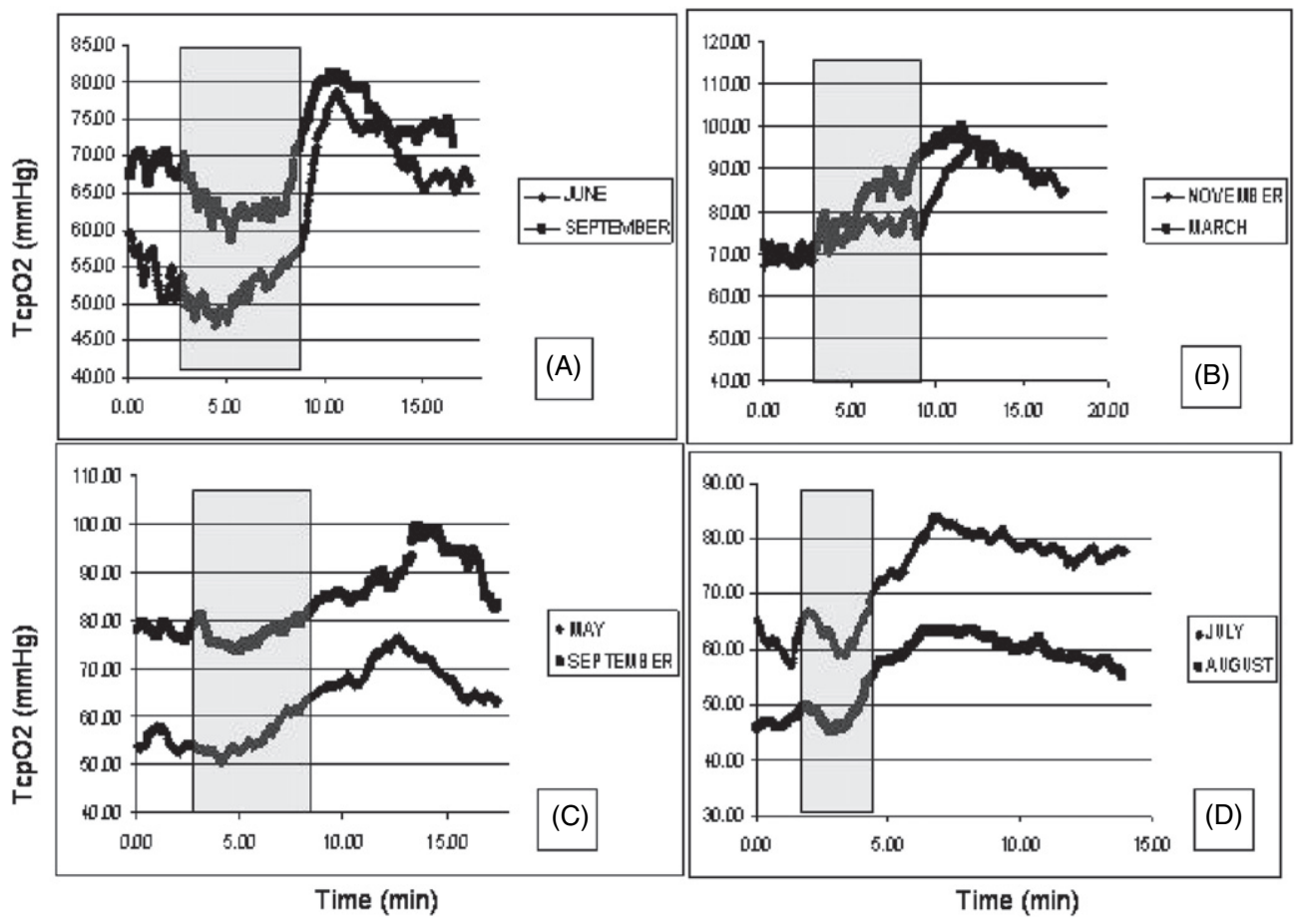

Figure 6. Examples of test-retests recordings in four different patients. Grey squares show the walking periods of the first test. Patient 'A' shows type 9 profiles on the two tests separated by 3 months. Note that the walking lasted $1 \mathrm{~min}$ less at the second test. The other three patients have type 1 profiles with intervals between tests ranging 1 to 4 months. Walking duration was almost the same at the two tests.

\section{Discussion}

Characterization of the chest $\Delta \mathrm{tcpO}_{2}$ profile during treadmill walking tests can be easily done with the cross correlation technique through an Excel spreadsheet. This study suggests that most of the tcpO $\mathrm{O}_{2}$ changes observed can be classified into only four of nine pre-defined profile types, among which approximately $75 \%$ to $80 \%$ patients showed assumed normal changes. The distribution of profiles is reliable in a prospective study of a population different from the population of experiment 1 . The $\Delta \mathrm{tcpO}_{2}$ profiles are independent of the position of the probes. They are also reproducible in test-retest recordings and thus seem characteristic of each patient's response to treadmill walking.

The physiological effects of exercise include an increase in the total ventilation, an increase in the tidal volume and an improvement of the ventilation to perfusion ratio. These mechanisms are expected to result in an increase in arterial $\mathrm{pO}_{2}$ at least for mild to moderate exercise in both normal and diseased subjects (Rubin et al 1982). Then changes in $\mathrm{tcpO}_{2}$ fitting the type 1 and 2 models follow the expected changes in arterial $\mathrm{pO}_{2}$. Thus, it is likely that these two tcpO $\mathrm{O}_{2}$ profiles (types 1 and 2) can be considered normal profiles. The second most frequently observed profile in experiment 1 and the largely represented profile in experiment 2 was of type 9 and consisted of an abrupt decrease at exercise start followed by a slow upward drift during walking, a recovery overshoot (values higher that starting values) and finally a slow decrease during the late recovery period, referred to here as walking-induced transcutaneous 
hack (WITH). Post-exercise overshoots have been reported in the literature. The presence of post-exercise ejection fraction overshoot was reported in normal subjects and cardiac-diseased patients (Kano et al 1997, Kubota and Zoladz 2005). Other possible explanations for the $\Delta \mathrm{tcpO}_{2}$ overshoot are the presence of post-exercise metabolic hyperactivity in type 1 fibres following sub-maximal exercise (Sahlin et al 1997, Korzeniewski and Zoladz 2005) or abrupt changes in venous oxygen content (Sumimoto et al 1993). The overshoots we found strongly resemble the overshoots observed by Hugues (Hughes et al 1984) with both transcutaneous and iterative intra-arterial samplings in patients with pulmonary emphysema. These WITH profiles are somewhat different from those that we expected to find in exercise-induced arterial hypoxemia (EIAH). Indeed, in EIAH, arterial $\mathrm{pO}_{2}$ (and then $\mathrm{tcpO}_{2}$ ) is expected to decrease progressively throughout exercise, to reach a minimum at the end of exercise and to normalize progressively after the exercise as in type 5 and 8 models. It should be noted here that EIAH was described mainly for progressive or constant but heavy-load exercises and that little is known about $\mathrm{pO}_{2}$ changes occurring during moderate constant-load exercise. Whether the transient initial decrease and recovery overshoot of tcpO $\mathrm{O}_{2}$ observed for constant-load moderate exercise (WITH profile: type 9) would change to a progressive decrease throughout exercise and progressive recovery for incremental or heavy-load constant exercise (consistent with EIAH) is an interesting assumption that requires future experiments. The type 4 model appears to be a combination of the models expected to occur as a result of EIAH (types 5 and 8) with a progressive exercise-induced decrease and of the recovery overshoot observed in type 9 model (WITH profile). It is very likely that it represents an abnormal response during exercise, with a rapid post-exercise normalization.

It could be proposed that the WITH profiles, observed on $\Delta \mathrm{tcpO}_{2}$ values, result from cutaneous vasoconstriction during the sole exercise period. Although the potential competition between muscle and skin blood flow is known for years (Bevegard and Shepherd 1967) and occurs specifically at the outset of exercise, it is dependent on the level of exercise. Further, during sub-maximal exercise muscle metaboreflex stimulation is capable of modulating cutaneous vascular conductance in glabrous, but not in the nonglabrous chest skin (Kondo et al 2003). Specifically cutaneous vascular conductance increased (and not decreased) during handgrip exercise at the chest level (Kondo et al 2003). Since the work load performed on treadmill in our study is independent of the estimated cardiac or pulmonary capacity of the patients, it cannot be excluded that the workload performed may represent a high percentage of the maximal capacity in some patients. Whether, the WITH profiles occur specifically in patients with altered cardio-respiratory function as a reflex cutaneous vasoconstrictor response to a high level of exercise, relative to their maximal exercise capacity, is an interesting assumption. The presence of a WITH profile would then be an indirect index of impaired cardiovascular function. In such a case arterial $\mathrm{pO}_{2}$ and saturation would remain stable while transcutaneous $\mathrm{pO}_{2}$ decreases due to cutaneous vasoconstriction. Future studies are needed to compare tcpO $\mathrm{O}_{2}$ results to saturation or direct arterial sampling in the detection of abnormal exercise arterial oxygen transport responses in our population. Whatever, assuming that WITH profiles reflect a transient fall in arterial oxygen pressure that slowly increases when exercise is continued, it is likely that only a transient decrease of $\mathrm{SaO}_{2}$ will occur at exercise onset in such patients in starting arterial $\mathrm{pO}_{2}$. Such a transient decrease will hardly be differentiated from a technical problem in saturation recording. Lastly, it is of particular interest to note that if a direct arterial blood sampling was performed in these patients in the last seconds of exercise (as done in most cases when searching for exercise induced hypoxemia), the arterial $\mathrm{pO}_{2}$ might not be (or only slightly be) decreased as compared to resting values. At worse, if the blood sampling is done a few seconds after the end of exercise for technical reasons (difficult puncture, delayed sampling, abrupt stop), arterial $\mathrm{pO}_{2}$ shall be higher than the resting 
value leading to the exclusion of an abnormal (or at least unusual and suspect) $\mathrm{pO}_{2}$ response to exercise. A study (the 'initial VHS study') is currently ongoing to perform a direct comparison of $\Delta \mathrm{tcpO}_{2}$ changes to arterial $\mathrm{pO}_{2}$ changes through multiple iterative sampling throughout the rest, exercise and recovery periods. Preliminary results seem to confirm that arterial $\mathrm{pO}_{2}$ changes do follow $\Delta \mathrm{tcpO} \mathrm{P}_{2}$ changes with an initial transient $\mathrm{pO}_{2}$ decrease at outset of walking and that a recovery overshoot similar to the ones observed by Hughes (Hughes et al 1984) is found.

When classification was performed prospectively in a second group, the first three most frequently observed $\Delta \mathrm{tcpO} \mathrm{O}_{2}$ profiles were of types 1,2 and type 9 . The results observed in table 2 of the present study are strongly concordant to those found in experiment 1 . Last, reproducibility of the $\Delta \mathrm{tcpO}_{2}$ profile in intra-test and test-retest recordings was good. Although our environmental conditions are standardized in the laboratory, we think that the average 5 months delay between the two tests in experiment 4 precludes that the changes observed are independent of the patient's physiological adaptation to exercise.

\section{Conclusion and perspectives}

A prospective study has to be carried out including both haematological and respiratory tests and the comparison of the results observed between the different $\Delta \mathrm{tcpO}_{2}$ categories has to be made. The underlying mechanisms and eventually associated diseases that could be found in patients showing WITH remain to be studied. Among these, exercise-induced right-to-left shunts are potential candidates.

\section{Acknowledgments}

The authors thank Mrs I Laporte for technical help. Clinical trial registration: NIH database: NCT00152737 for experiments 3 and 4, not applicable to the observational study of experiments 1 and 2. PA benefits from a research 'Interface' grant from the INSERM (Institut National de la Santé et de la Recherche Médicale) and has benefited from the not-for-profit support $(<2000 €)$ of the Radiometer Company for conference on 'oxygen measurements' during the 2010 congress of the French Society of Physiology.

\section{References}

Abraham P, Picquet J, Bouye P, L'Hoste P, Enon B, Vielle B and Saumet J L 2005 Transcutaneous oxygen pressure measurements $\left(\mathrm{tcpO}_{2}\right)$ at ankle during exercise in arterial claudication Int. Angiol. 24 80-8

Abraham P, Picquet J, Vielle B, Sigaudo-Roussel D, Paisant-Thouveny F, Enon B and Saumet J L 2003 Transcutaneous oxygen pressure measurements on the buttocks during exercise to detect proximal arterial ischemia: comparison with arteriography Circulation 107 1896-900

Arnold T, Karabinis V, Sano C, Gensler T, Ugaeri H, Samuels L, Sariego J, Kerstein M and Matsumoto T 1993 Revascularized diabetic limbs: positional changes in regional perfusion index Am. Surg. 59 746-9

Bevegard B S and Shepherd J T 1967 Regulation of the circulation during exercise in man Physiol. Rev. 47 178-213

Brudin L, Berg S, Ekberg P and Castenfors J 1994 Is transcutaneous $\mathrm{PO}_{2}$ monitoring during exercise a reliable alternative to arterial $\mathrm{PO}_{2}$ measurements? Clin. Physiol. 14 47-52

Caillard P, Mouren X, Pujade B, Blanchemaison P, Elbeze Y and Cloarec M P 1990 Objectifying exercise ischemia in peripheral vascular disease: a study in 120 patients Angiology $41469-78$

Carter R and Banham S W 2000 Use of transcutaneous oxygen and carbon dioxide tensions for assessing indices of gas exchange during exercise testing Respir. Med. 94 350-5

Clough R A, Leavitt B J, Morton J R, Plume S K, Hernandez F, Nugent W, Lahey S J, Ross C S and O'Connor G T 2002 The effect of comorbid illness on mortality outcomes in cardiac surgery Arch. Surg. 137 428-32 432-23 discussion 
Gelis A, Fattal C, Dupeyron A, Perez-Martin A, Colin D and Pelissier J 2009 Reproducibility of transcutaneous oxygen pressure measurements in persons with spinal cord injury Arch. Phys. Med. Rehabil. 90 507-11

Grouiller F, Jaquinandi V, Picquet J, Souday V, Saumet J L and Abraham P 2006 Validation of a new device for transcutaneous oxygen pressure recordings in real and simulated exercise tests Int. Angiol. 25 190-6

Heidrich H 2004 Frequency of non-vascular accompanying diseases in patients with peripheral arterial disease Vasa 33 155-8

Hughes J A, Gray B J and Hutchison D C 1984 Changes in transcutaneous oxygen tension during exercise in pulmonary emphysema Thorax 39 424-31

Hutchison D C, Gray B J, Callaghan J M and Heaton R W 1987 Transcutaneous oxygen tension during exercise in patients with pulmonary emphysema Adv. Exp. Med. Biol. 220 67-70

Kano H, Koike A, Yajima T and Hirakoba K 1997 Mechanism of human muscle after sustained submaximal exercise Chest 273 C172-8

Killian K J, Leblanc P, Martin D H, Summers E, Jones N L and Campbell E J 1992 Exercise capacity and ventilatory, circulatory, and symptom limitation in patients with chronic airflow limitation Am. Rev. Respir. Dis. 146 935-40

Kondo N, Yanagimoto S, Nishiyasu T and Crandall C G 2003 Effects of muscle metaboreceptor stimulation on cutaneous blood flow from glabrous and nonglabrous skin in mildly heated humans J. Appl. Physiol. 94 1829-35

Korzeniewski B and Zoladz J A 2005 Some factors determining the PCr recovery overshoot in skeletal muscle Biophys. Chem. 116 129-36

Kubota S and Zoladz J A 2005 Mechanism of overshoot in skeletal muscle Kaku Igaku 32 129-36

Machin D C M, Fayers P and Pinol A 1997 Sample Size Tables for Clinical Studies 2nd edn (Oxford: Blackwell Science) pp 168-71

Mcdowell J W and Thiede W H 1980 Usefulness of the transcutaneous $\mathrm{PO}_{2}$ monitor during exercise testing in adults Chest 78 853-5

Osmundson P J, Rooke T W and Hallett J W 1988 Effect of arterial revascularization on transcutaneous oxygen tension of the ischemic extremity Mayo Clin. Proc. 63 897-902

Planes C, Leroy M, Foray E and Raffestin B 2001 Arterial blood gases during exercise: validity of transcutaneous measurements Arch. Phys. Med. Rehabil. 82 1686-91

Rubin S A, Brown H V and Swan H J 1982 Arterial oxygenation and arterial oxygen transport in chronic myocardial failure at rest, during exercise and after hydralazine treatment Circulation 66 143-8

Sahlin K, Soderlund K, Tonkonogi M and Hirakoba K 1997 Phosphocreatine content in single fibers of human muscle after sustained submaximal exercise Am. J. Physiol. 273 C172-8

Sridhar M K, Carter R, Moran F and Banham S W 1993 Use of a combined oxygen and carbon dioxide transcutaneous electrode in the estimation of gas exchange during exercise Thorax 48 643-7

Sumimoto T, Sugiura T, Takeuchi M, Yuasa F, Iwasaka T and Inada M 1993 Overshoot in mixed venous oxygen saturation during recovery from supine bicycle exercise in patients with recent myocardial infarction Chest 103 514-20

von Kemp K, van den Brande P, Peterson T, Waegeneers S, Scheerlinck T, Danau W, van Tussenbroek F, Debing E and Staelens I 1997 Screening for concomitant diseases in peripheral vascular patients. Results of a systematic approach Int. Angiol. 16 114-22 